\title{
Prioritising action on occupational carcinogens in Europe: a socioeconomic and health impact assessment
}

J W Cherrie ${ }^{* 1,2}$, S Hutchings ${ }^{3}, \mathrm{M}$ Gorman $\mathrm{Ng}^{1,6}, \mathrm{R}$ Mistry ${ }^{4,7}, \mathrm{C}$ Corden $^{4}$, J Lamb ${ }^{1,8}$, A Sánchez Jiménez ${ }^{1}$, A Shafrir ${ }^{1,9}, \mathrm{M}_{\text {Sobey }}{ }^{4,10}, \mathrm{M}$ van Tongeren ${ }^{1,5}$ and L Rushton ${ }^{3}$

${ }^{1}$ Institute of Occupational Medicine, Research Avenue North, Edinburgh EH14 4AP, UK; ${ }^{2}$ Institute of Biological Chemistry, Biophysics and Bioengineering, Heriot Watt University, Edinburgh EH14 4AS, UK; ${ }^{3}$ Department of Epidemiology and Biostatistics, Imperial College London, St Mary's Campus, Norfolk Place, London W2 1PG, UK; ${ }^{4}$ Amec Foster Wheeler Environment \& Infrastructure UK Limited, 12th Floor, 25 Canada Square, London E14 5LQ, UK and ${ }^{5}$ Centre for Occupational and Environmental Health, Centre for Epidemiology, Division of Population Health, Health Services Research and Primary Care, School of Health Sciences, Faculty of Biology, Medicine and Health, The University of Manchester, Oxford Road, Manchester M13 9PL, UK

Background: Work-related cancer is an important public health issue with a large financial impact on society. The key European legislative instrument is the Carcinogens and Mutagens Directive (2004/37/EC). In preparation for updating the Directive, the European Commission commissioned a study to provide a socioeconomic, health and environmental impact assessment.

Methods: The evaluation was undertaken for 25 preselected hazardous substances or mixtures. Estimates were made of the number of cases of cancer attributable to workplace exposure, both currently and in the future, with and without any regulatory interventions, and these data were used to estimate the financial health costs and benefits.

Results: It was estimated that if no action is taken there will be $>700000$ attributable cancer deaths over the next 60 years for the substances assessed. However, there are only seven substances where the data suggest a clear benefit in terms of avoided cancer cases from introducing a binding limit at the levels considered. Overall, the costs of the proposed interventions were very high (up to $€ 34000$ million) and the associated monetised health benefits were mostly less than the compliance costs.

Conclusions: The strongest cases for the introduction of a limit value are for: respirable crystalline silica, hexavalent chromium, and hardwood dust.

There are $>3$ million cancers recorded in the European Union each year and about 1.7 million cancer deaths, predominantly lung, colorectal, breast and stomach cancer (Ferlay et al, 2007). Recent research in Britain has shown that approximately 1 in 20 cancer deaths may be attributable to work (about 8 in men and $2 \%$ in women), with mesothelioma, sinonasal, lung, nasopharyngeal and breast cancer in women having the greatest proportion of cases due to work (Rushton et al, 2012). The main agents contributing to the

\footnotetext{
${ }^{\star}$ Correspondence: Professor JW Cherrie; E-mail: john.cherrie@iom-world.org

${ }^{6}$ Current address: School of Population and Public Health, University of British Columbia, 2206 E Mall, Vancouver, BC V6T 1Z9, Canada.

${ }^{7}$ Current address: Economics for the Environment Consultancy Ltd, 73-75 Mortimer Street, London W1W 7SQ, UK.

${ }^{8}$ Current address: The Royal Zoological Society of Scotland, Edinburgh Zoo, 134 Corstorphine Road, Edinburgh EH12 6TS, UK.

${ }^{9}$ Current address: Division of Adolescent/Young Adult Medicine, Boston Center for Endometriosis, Boston Children's Hospital and Harvard Medical School, 1 Autumn Street, Boston, MA 02215, USA.

${ }^{10}$ Current address: Adam Smith International, 240 Blackfriars Road, London SE1 8NW, UK.
}

Received 10 January 2017; revised 2 May 2017; accepted 16 May 2017; published online 13 June 2017

(C) 2017 Cancer Research UK. All rights reserved 0007-0920/17 
workplace cancer burden in Britain are asbestos, shift-work involving night work, mineral oils, solar radiation, silica, diesel engine exhaust (DEE), coal tars and pitches, occupation as a painter or welder, dioxins, environmental tobacco smoke, radon, tetrachloroethylene, arsenic and strong inorganic acid mists. Purdue et al (2015) reviewed published reports with quantitative estimates of the population attributable fraction (AF) for all cancer from occupational exposures. Estimates ranged between 2 and 8\%, with the values for men ranging 3-14\% and for women from 1 to $2 \%$. The highest estimate was from Finland: 14, men and 2\%, women (Nurminen and Karjalainen, 2001).

In Europe, Directive 2004/37/EC on the Protection of Workers from the Risks Related to Exposure to Carcinogens or Mutagens at Work (the Carcinogens Directive) provides a common legislative framework for managing occupational cancer risks (The Directive was amended in $2014(2014 / 27 / \mathrm{EC})$ in order to align them to Regulation (EC) No $1272 / 2008$ on classification, labelling and packaging of substances and mixtures.). The Directive sets out general strategies for workplace risk management and includes requirements for assessment of risks, prevention or reduction of exposure and other elements of a risk management strategy. The scope includes supplied substances classified as category $1 \mathrm{a}$ or $1 \mathrm{~b}$ carcinogens under the European Classification, Labelling and Packaging (CLP) Regulations (European Regulation (EC) No 1272/2008) but at the moment does not include most process-generated carcinogenic substances, such as DEE or crystalline silica. In addition, there are currently only three carcinogenic agents with specified occupational exposure limits (benzene, vinyl chloride monomer and inhalable hardwood dust). Each European country implements the Directive into their national law.

The European Commission DG Employment, Social Affairs, Inclusion (DG EMPL) is in the process of updating the Carcinogens Directive to address some of the perceived limitations and to extend the scope to include additional substances. As part of this work, we have undertaken a socioeconomic, health and environmental analysis of possible changes to the Carcinogens Directive for 25 occupational carcinogenic substances identified by DG EMPL for possible inclusion in a revision to the Directive (Table 1). In particular, we assessed the potential impact of introducing legally binding occupational exposure limits (OELs), specified as 8 -h time weighted average air concentrations. This paper summarises the methodology and main results from the health and economic assessments, which was the main focus for the work. The detailed reports from the project, including the more limited social and environmental assessments, are available and can be found on the European Commission website (links provided in the Supplementary Information 3 document).

\section{METHODS}

Overview. The burden of cancer due to past and predicted future occupational use of the 25 carcinogens (note that rubber process dust and fume were evaluated separately) was estimated using the general methodology developed for the British burden of occupational cancer study (Rushton et al, 2012). The health costs of these cancers were then estimated assuming (i) that no changes in exposure occurred (baseline) and (ii) for intervention scenarios in which OELs are introduced or existing OELs in the Directive are reduced. OEL values were either suggested by the European Commission or were identified as being 'typical' of values in EU member states. For some carcinogens, up to three different OELs were separately assessed. Costs to industry of compliance with the new OEL values were also estimated for each intervention scenario.
This enabled the costs and benefits of the 'do nothing' scenario to be compared with the intervention scenarios.

Exposure data. Information about the uses and/or circumstances of exposure for each substance, together with additional information provided by stakeholders, was used to assess the exposures in the European working population. The main sources of information to estimate prevalence of exposure were:

- Labour Force Survey (LFS) and EU wide structural business statistics (SBS) data from EUROSTAT (http://ec.europa.eu/ eurostat/help/new-eurostat-website);

- CAREX for 15 EU countries (1993), updated in Finland for 2000 and 2007, in Spain and in Italy for the period 2000-2003 (Kogevinas et al, 2000; Mirabelli and Kauppinen, 2005);

- WOODEX-database with estimates of prevalence and levels of wood dust exposure for $25 \mathrm{EU}$ countries by industry (Kauppinen et al, 2006); and

- Information from stakeholders, such as trade associations.

Exposure prevalence data were available from CAREX for all the agents with the exception of: rubber fumes and dust, mineral oils as used engine oils, 1,2-epoxypropane, 1-chloro-2,3-epoxypropane, 2nitropropane, and 4,4'-methylenedianiline. Exposure prevalence for rubber fumes and dust exposure was estimated from the SBS data. Exposure prevalence for the remaining agents came from information collected from trade associations and other stakeholders. The information from CAREX and other sources were combined with data from EUROSTAT to obtain estimates of exposure prevalence.

The level or intensity of exposure was assessed using:

- published scientific literature;

- information from European Risk Assessment Reports compiled in relation to the EU Existing Substances Regulations;

- the Woodex database for hardwood dust;

- the Exasrub database for rubber dust (de Vocht, 2005); and

- information provided by industry stakeholders.

Temporal changes in exposure were determined using information from the literature, which was ideally specific to the substance being considered, but in situations where this was not available, and it was our view that there was a decline in exposure levels over time, we relied on the results from a systematic review of the literature (Creely et al, 2007).

Statistical methods. The statistical methodology for estimating the burden of occupational cancer was based on that developed for the British occupational cancer study (Hutchings and Rushton, 2012a). Levin's formula was used to estimate the AF, that is, the proportion of cases due to occupational exposure (Levin, 1953). This requires an estimate of the risk of disease, for example, relative risk (RR), obtained from published literature and the proportion of the population exposed, derived from data sources described above, while accounting for employment turnover and life expectancy, and adjusted for employment trends. A risk exposure period (REP) was defined as the relevant exposure period accounting for cancer latency (10-50 years for solid tumours, 0 20 years for blood cancers). RRs were selected for 'high' and 'low' exposure levels and industries were allocated accordingly.

For predicting future burden, the risk exposure windows were projected forward in time, and estimation was carried out for a series of forecast target years (FTYs) that stretch far enough into the future to account for the latency of cancers currently being initiated, that is, to the decade starting 2060 (Hutchings and Rushton, 2012b). The method enables predictions to be made for a range of alternative scenarios of change, for example, reducing exposure limits or improvement in compliance. For this study, the 
Table 1. Substances and cancer sites evaluated

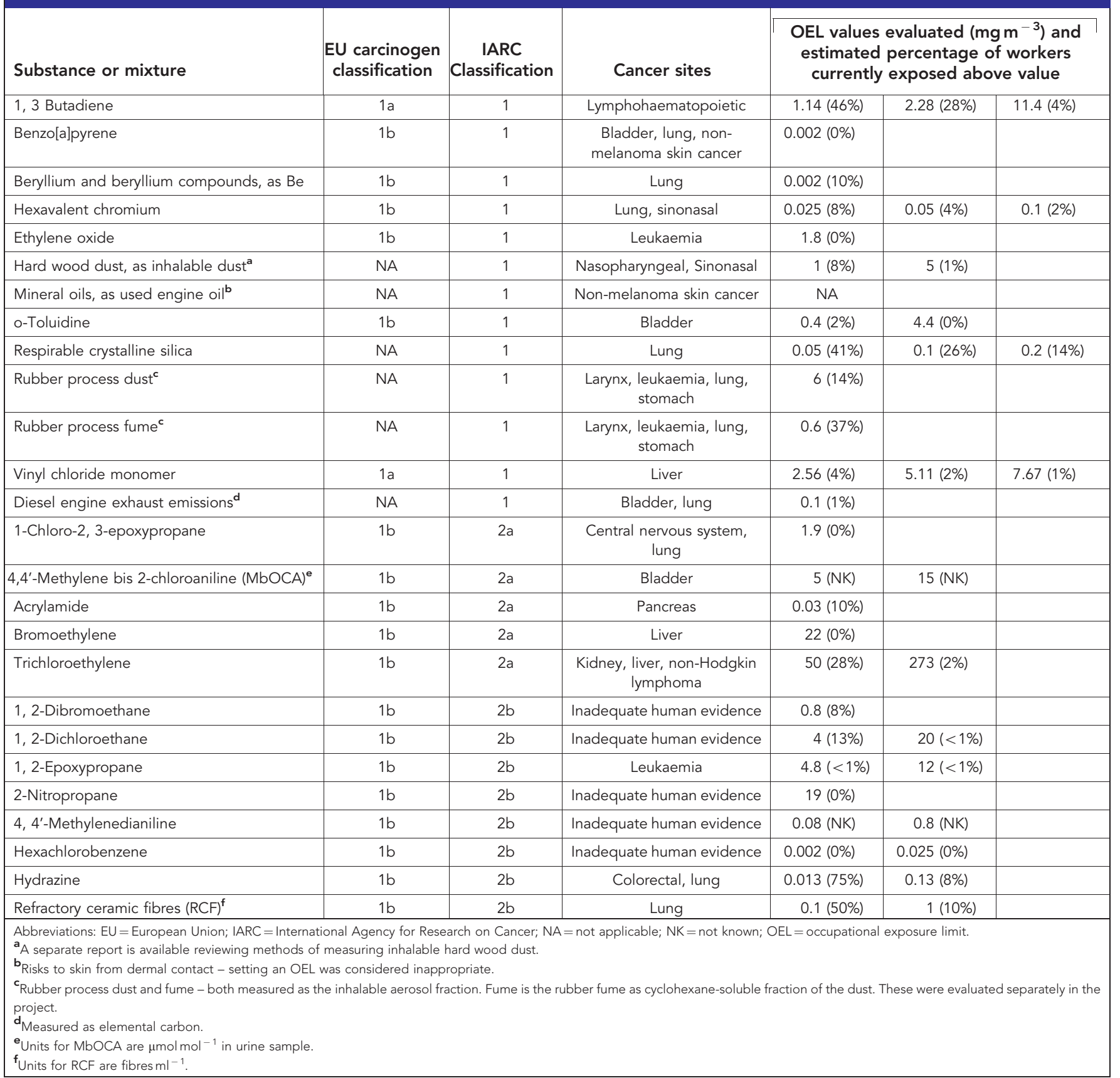

European Commission asked us to investigate introduction in 2010 of new OELs or the reduction of existing exposure limits for the substances and to assume that there would be 'full compliance' with the OEL from the date it was introduced, that is, that $>99 \%$ of exposures in the EU would be less than the limit value. Where a substance was banned or usage had been restricted in the past, then these changes were reflected in the exposure prevalence data used for estimation of future burden.

Projected changes in the number of exposed workers were based on historic changes in the numbers employed in grouped main industry sectors from the EU LFS. Projections of cancer deaths and registrations for the FTYs were based on current rates (2006 for deaths, generally 2002 for registrations) applied to EU country-specific population projections by age. Trends in employment and exposure were applied until 2030 and remained steady thereafter.
Results from projections in the future, based on the pattern of past and current exposure and intervention scenarios, were compared with a baseline scenario that assumes no change in exposed numbers or exposed levels beyond 2010 to assess relative impact on reducing attributable numbers of cancers. We calculated the number of avoided cases as a consequence of introducing the proposed OELs. For used mineral oils, where there was no proposed OEL, no assessment was made of avoided cases.

Costs were based on estimated cancer registrations and associated disability-adjusted life-years (DALYs). DALYs are calculated as the sum of the years of life lost due to premature mortality (YLLs) and the years lost due to disability, reflected in a cost of illness (COI) or willingness-to-pay (WTP) to avoid the suffering and inconvenience of disease. One DALY represents 1 year of healthy life lost through early death or living with a disability. The costs of health impacts were estimated for: 
1. the value of life years lost (VLYL) by multiplying the YLLs by an estimate of VLYL; $€ 50000$ was used for the minimum VLYL and $€ 100000$ for the maximum (European Commission, 2009).

2. the COI; this includes the direct (such as inpatient, outpatient home care), indirect (such as loss of income) and intangible costs (disfigurement, functional limitations).

Further discussion of the cost estimates used in this study can be found in Supplementary Material online (Methodology for valuing health impacts on the SHEcan project).

Information required for the estimation of the COI for each type of cancer is scarce and therefore has been taken from existing studies related to cancer. Rabl (2004) provides values of unit costs (i.e., per patient) that are used in France for different morbidity risks and includes estimates for COI and WTP. Their estimate $(€ 48600)$ has thus been used for all cancers. Future health costs were discounted at the same annual rate (4\%) as compliance cost estimates. Sensitivity analysis was carried out using both a declining discount rate and no discounting. As the health impacts occur over a long period of time relative to compliance costs, the impacts of discounting can have a significant impact on the overall size of the monetised health benefits.

We considered the compliance costs of meeting the proposed amendments to the Directive, particularly the introduction of a limit value. To do this, we identified the main uses leading to exposures that are in excess of the proposed OEL and the industry sectors in which those uses take place. Minor uses were considered but not assessed in detail. Information sources on likely compliance costs were limited. For example, in relation to hard wood dust we relied on a report from a campaign by the French Ministry of Labour, which involved around 3100 visits to wood-working sites, supplemented by attempts to obtain information from relevant trade associations and ventilation suppliers.

Consideration was given to the possible risk management measures (RMM) that may be applied in order to meet the investigated OEL and whether these RMM may have already been applied - in some countries or all EU countries. Background information on all agents in the project were obtained from published literature and stakeholder contacts to identify:

- the uses and activities that lead to workplace exposure;

- the structure of the sectors in which exposure occurs: (e.g., numbers employed demographics of employees and geographical distribution of firms in the EU);

- exposure control measures currently in place, available and required to meet the proposed OEL; and

- the possible costs of exposure control measures.

In order to understand the economic impacts on sectors in which specific uses cause a risk to the health of workers, we used publicly available data from EUROSTAT to define the number of enterprises operating in different sectors, the number of workers employed in those enterprises, the distribution of enterprises in the EU and financial measures such as turnover, personnel costs and research and development expenditure.

Estimates were made of:

- the number of firms needing to apply RMMs and the estimated cost of the RMMs over the same time period as health benefits (2010-69);

- the cost of the administrative burden of implementing the OEL (e.g., the cost of monitoring and audit); and

- the potential effect on the market for the substance by the imposition of the OEL.
The final analysis comprised a comparison of the costs and benefits of the 'do nothing' or 'business as usual' situation with the scenario in which the possible OEL is added to the Directive.

\section{RESULTS}

The 25 substances considered are listed in Table 1 with the IARC and EU carcinogen classifications. Twelve of the substances considered were definite human carcinogens (International Agency for Research on Cancer, Group 1), four were probable human carcinogens (IARC 2a) and nine were possible human carcinogens (IARC 2b). There are $>10$ different types of cancer that may be caused by exposure to these substances, most commonly lung and bladder cancer (Table 1). For some of these tumour types, survival is good, for example, non-melanoma skin cancer that may be caused by mineral oils as used engine oil or benzo[a]pyrene, although for most of the cancers the prognosis is relatively poor.

Details of the OELs evaluated are also shown in Table 1 along with estimates for the percentage of EU workers currently exposed above the limit. The OEL values for five substances were suggested by the European Commission: hard wood dust, vinyl chloride monomer, hexavalent chromium, respirable crystalline silica, and 1,3 Butadiene. All others were selected as 'typical' of existing OEL values among EU member states (note that the OEL for DEE was from Austria, as this was the only one available). For some OEL values, there is a relatively large proportion of workers judged to be currently exposed above the limit, for example, $75 \%$ of workers exposed above a possible hydrazine limit of $0.013 \mathrm{mg} \mathrm{m}^{-3}$. For 14 substance-OEL combinations, including DEE, there are $<1 \%$ of workers currently exposed above the suggested limit value representing nearly full compliance; for these, there is little or no health benefit from introducing an OEL at that value.

The estimated number of workers currently exposed in the EU ranges from $<1000$ for bromoethylene to $>7$ million for benzo[a]pyrene (Figure 1). There is very little information on the number of workers who are be exposed to $4,4^{\prime}$-methylenedianiline (MDA), although there are probably about $>400000$ handling this substance. The number exposed to hexachlorobenzene is unknown, as, although use of this substance is banned in the EU, some exposure is thought to occur as a by-product of a small number of processes.

For two substances (ethylene oxide, bromoethylene), there were no deaths predicted from past or future exposures. No baseline health impact was made for five substances, because there was insufficient epidemiological evidence (1,2-dichloroethane, 1,2dibromoethane, hexachlorobenzene and 2-nitropropane) or exposure data (MDA) to carry out these assessments. The results for cancer mortality and cancer incidence for the remaining 18 carcinogens (with rubber dust and fume presented separately) are given in Table 2 for the baseline year (2010) and for the predicted period 2010-2069 under the baseline assessment, that is, assuming 'do nothing', together with estimated numbers of cancer cases prevented by introducing an OEL at specified values and health and compliance costs.

Table 2 shows that for nine substances it was estimated that there would be $>1000$ cancer deaths occurring in the EU over the next 60 years if no action is taken; total estimated attributable cancer deaths from these nine substances over this period were in excess of 700000 . The greatest numbers of excess incident cancers were predicted for respirable crystalline silica, DEE and mineral oils as used engine oils. The predicted number of future cancer deaths is broadly related to the estimated number of workers currently exposed (Figure 2).

There are only seven substances or mixtures where the data suggest a clear health benefit in terms of avoided cancer cases over 


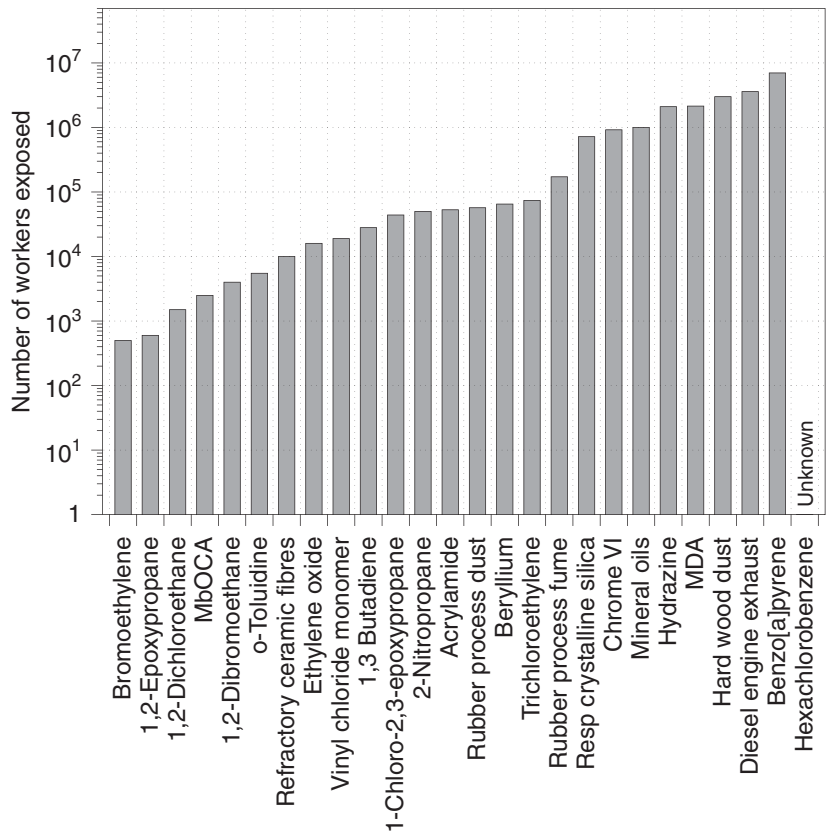

Figure 1. Number of workers exposed over the risk exposure period by carcinogen.

the next 60 years from introducing an OEL at the specified values. The largest benefits arise from the introduction of OELs for respirable crystalline silica, hardwood dust, hexavalent chromium and rubber fume. The highest percentage reduction in incident cases was for the OEL for rubber fume (39\%), followed by hardwood dust at $1 \mathrm{mg} \mathrm{m}^{-3}(28 \%)$ and respirable crystalline silica at $0.05 \mathrm{mg} \mathrm{m}^{-3}(23 \%)$. For 26 of the 36 substance-OEL combinations where a health assessment was possible, there were minimal health benefits from the introduction of an OEL at the proposed level, that is, $<20$ cancer cases avoided over the next 60 years.

Generally, where $>1000$ cancers were predicted to occur over the coming 60 years, the baseline health costs were estimated to be $>€ 1000$ million. The two largest estimated health baseline costs were for respirable crystalline silica (between $€ 190000000$ and $€ 490000000$ million) and DEE (€99000$€ 260000$ million).

Estimated compliance costs ranged from 0 to $>€ 100000$ million over the next 60 years. It was judged that for 14 substanceOEL combinations the compliance cost could exceed $€ 1000$ million. Highest costs were for hexavalent chromium, respirable crystalline silica, MDA along with beryllium and beryllium compounds. Four substance-OEL combinations were judged as likely to have a substantial negative impact on small- and mediumsize enterprises (respirable crystalline silica - for two of the limits evaluated, beryllium and hard wood dust) and in a further six cases it is possible there could be a substantial negative impact on SMEs from introducing a proposed OEL.

The monetised health benefits from introducing an OEL were greatest for respirable crystalline silica (between $€ 21000$ and $€ 74000$ million, depending on the OEL and the uncertainties involved in the estimation). Health benefits were also large for the introduction of OELs for hexavalent chromium (around $€ 500-€ 1300$ million for a limit of $0.025 \mathrm{mg} \mathrm{m}^{-3}$ ) and rubber process fume (€580-€1200 million).

The monetised benefit-to-cost ratio was less than one in all substance-OEL combinations except for respirable crystalline silica (all three potential OEL values exceeded one, showing a net estimated benefit from introducing an OEL), rubber process fume

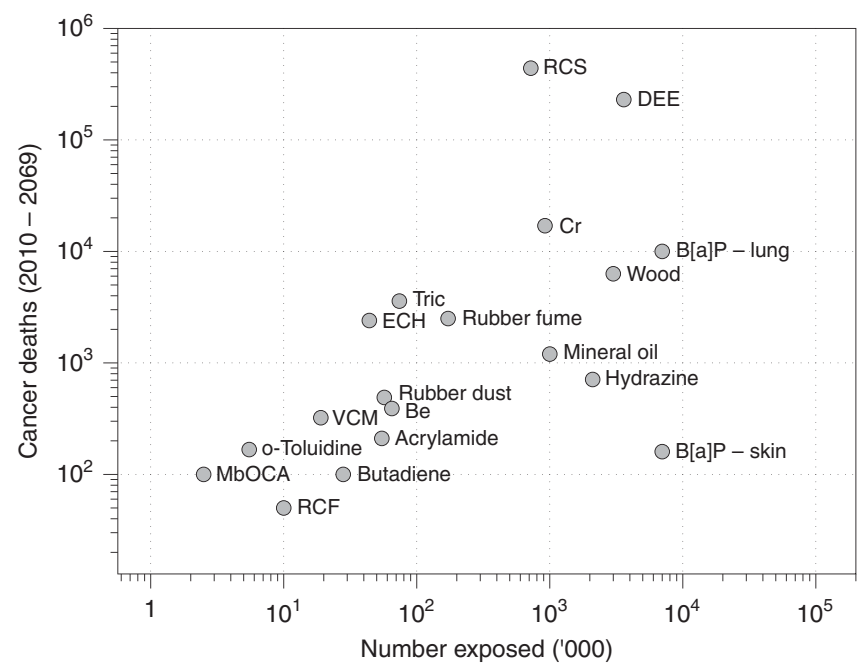

Figure 2. Baseline health impact (mortality) in 2010 vs the number of workers exposed.

and trichloroethylene $\left(50 \mathrm{mg} \mathrm{m}^{-3}\right)$. This provides an indication that the costs of intervention may be less than the benefits, although it should be noted that these comparisons are strongly dependent on the rate used for discounting of future costs and benefits, because the majority of the compliance costs occur at the outset, whereas the majority of the benefits occur in the future. For each substance, we carried out a sensitivity analysis to assess the impact of discounting on the monetised benefits. For example, for wood dust for an OEL of $1 \mathrm{mg} \mathrm{m}^{-3}$ the total health benefit without discounting was $€ 333-€ 1600$ million, which reduced to $€ 51-€ 252$ million with discounting. Similar reductions were seen for other substances; full details are provided in the individual substance reports that are available online.

\section{DISCUSSION}

As part of the effort to reduce occupational cancers, we have undertaken a socioeconomic and health analysis to assess the potential impact of introducing legally binding OELs or reducing those already existing for 25 workplace carcinogens. When evaluating these results and making recommendations for action, we have used a pragmatic weight of evidence approach including taking into account: the numbers of workers currently exposed across the EU and the exposure levels, the numbers of predicted deaths and newly occurring cancers if no action is taken, the size of the risks associated with the cancers of concern, the costs to health and to industry, and the cost-benefit ratios. The detailed evidence for our evaluations is summarised for each substance in the online Supplementary Material (Weight of evidence arguments for prioritising substances for binding OELs).

The cost-benefit ratio together with predicted numbers of deaths as a result of inaction suggests that the strongest cases for the introduction of an OEL are for: respirable crystalline silica, hexavalent chromium, and hardwood dust. Other substances where the weight of evidence (for example, high risk estimates, high health burden with no action or many workers currently exposed) supports the introduction of a limit include: DEE emissions, rubber fume/dust, benzo[a]pyrene, trichloroethylene, hydrazine, epichlorohydrin, o-toluidine, mineral oils as used engine oil, and MDA. It should be noted that our health impact assessment considered only cancers as the end point. However, introducing limits for the above substances could also contribute to 
Table 2. Estimated incident cancers and cancer deaths at baseline, predicted cancers under the baseline scenario, predicted cancers prevented by introducing an OEL and health and compliance costs from 2010 to 2069

\begin{tabular}{|c|c|c|c|c|c|c|c|c|c|c|}
\hline $\begin{array}{l}\text { Substance } \\
\text { or mixture }\end{array}$ & $\begin{array}{c}\text { Baseline } \\
\text { incident } \\
\text { cancers } \\
2010\end{array}$ & $\begin{array}{c}\text { Predicted } \\
\text { incident } \\
\text { cancers } 2010- \\
2069 \text { under } \\
\text { baseline } \\
\text { scenario }\end{array}$ & $\begin{array}{c}\text { Baseline } \\
\text { deaths } \\
2010\end{array}$ & $\begin{array}{l}\text { Predicted } \\
\text { deaths } \\
\text { 2010-2069 } \\
\text { under } \\
\text { baseline } \\
\text { scenario }\end{array}$ & $\begin{array}{c}\text { OEL value } \\
\text { (mg m }^{-3} \\
\text { unless } \\
\text { stated } \\
\text { otherwise) }\end{array}$ & $\begin{array}{c}\text { Predicted } \\
\text { avoided incident } \\
\text { cancers 2010- } \\
2069 \text { from } \\
\text { implementing } \\
\text { the OEL }\end{array}$ & $\begin{array}{c}\% \\
\text { decrease } \\
\text { in health } \\
\text { risk }\end{array}$ & $\begin{array}{c}\text { Total } \\
\text { compliance } \\
\text { costs } \\
\text { (€ million) }\end{array}$ & $\begin{array}{c}\text { Total } \\
\text { health } \\
\text { benefits } \\
\text { ( } € \\
\text { million) }\end{array}$ & $\begin{array}{c}\text { Benefit- } \\
\text { to-cost } \\
\text { ratio }^{a}\end{array}$ \\
\hline \multirow[t]{3}{*}{$\begin{array}{l}\text { Respirable } \\
\text { crystalline silica }\end{array}$} & 7600 & 470000 & 6900 & 440000 & 0.2 & 80000 & $17 \%$ & 10000 & $\begin{array}{c}21000- \\
56000\end{array}$ & $2.3-5.4$ \\
\hline & & & & & 0.1 & 99000 & $21 \%$ & 19000 & $\begin{array}{c}26000- \\
68000\end{array}$ & $1.5-3.5$ \\
\hline & & & & & 0.05 & 110000 & $23 \%$ & 34000 & $\begin{array}{c}28000- \\
74000\end{array}$ & $0.9-2.1$ \\
\hline $\begin{array}{l}\text { Diesel engine } \\
\text { exhaust } \\
\text { emissions }\end{array}$ & 5700 & 270000 & 4600 & 230000 & 0.1 & 0 & 0 & $25-250$ & 0 & 0 \\
\hline $\begin{array}{l}\text { Mineral oils as } \\
\text { used engine oil }\end{array}$ & 900 & 130000 & 7 & 1200 & NA & Not assessed & & $46-920$ & Not assessed & - \\
\hline $\begin{array}{l}\text { Benzo[a]pyrene } \\
\text { Lung and } \\
\text { bladder } \\
\text { NMSC }\end{array}$ & $\begin{array}{l}600 \\
250 \\
\end{array}$ & $\begin{array}{l}13000 \\
18000 \\
\end{array}$ & $\begin{array}{c}480 \\
2 \\
\end{array}$ & $\begin{array}{r}10000 \\
160 \\
\end{array}$ & 0.002 & 0 & 0 & 0 & 0 & 0 \\
\hline \multirow[t]{3}{*}{$\begin{array}{l}\text { Hexavalent } \\
\text { chromium }\end{array}$} & 490 & 24000 & 380 & 17000 & 0.1 & 600 & $2.5 \%$ & $9000-37000$ & $159-456$ & $\begin{array}{c}0.006- \\
0.03\end{array}$ \\
\hline & & & & & 0.05 & 1400 & $5.8 \%$ & $18000-67000$ & $340-991$ & $\begin{array}{c}0.007- \\
0.03\end{array}$ \\
\hline & & & & & 0.025 & 1800 & $7.5 \%$ & $30000-115000$ & $461-1327$ & $\begin{array}{c}0.006- \\
0.03\end{array}$ \\
\hline \multirow[t]{2}{*}{ Hard wood dust } & 450 & 14000 & 200 & 6300 & 3 & 500 & $3.6 \%$ & 0 & $11-51$ & 0 \\
\hline & & & & & 1 & 3900 & $28 \%$ & $3800-8600$ & $61-297$ & $\begin{array}{c}0.01- \\
0.05\end{array}$ \\
\hline \multirow[t]{2}{*}{ Hydrazine } & 149 & 2500 & 43 & 710 & 0.13 & 0 & 0 & $15-47$ & 0 & 0 \\
\hline & & & & & 0.013 & 0 & 0 & $62-200$ & 0 & \\
\hline \multirow[t]{2}{*}{ Trichloroethylene } & 93 & 4800 & 59 & 3300 & 273 & 10 & $0.2 \%$ & 61 & 0 & 0 \\
\hline & & & & & 50 & 580 & $12 \%$ & 428 & $120-430$ & $0.3-1.0$ \\
\hline $\begin{array}{l}\text { Rubber process } \\
\text { fume }\end{array}$ & 61 & 3600 & 39 & 2500 & 0.6 & 1400 & $39 \%$ & $470-3200$ & $580-1200$ & $0.25-1.5$ \\
\hline $\begin{array}{l}\text { 1-Chloro-2,3- } \\
\text { epoxypropane }\end{array}$ & 34 & 2600 & 31 & 2400 & 1.9 & 0 & 0 & 0 & 0 & 0 \\
\hline \multirow[t]{2}{*}{ o-Toluidine } & 22 & 490 & 7 & 150 & 4.4 & 0 & 0 & 0 & 0 & 0 \\
\hline & & & & & 0.4 & & & & & \\
\hline $\begin{array}{l}\text { Rubber process } \\
\text { dust }\end{array}$ & 17 & 710 & 11 & 490 & 6 & 20 & $2.8 \%$ & $55-280$ & $24-46$ & $0.1-0.5$ \\
\hline \multirow{3}{*}{$\begin{array}{l}\text { Vinyl chloride } \\
\text { monomer }\end{array}$} & 14 & 300 & 14 & 300 & 7.67 & 0 & 0 & 0 & 0 & 0 \\
\hline & & & & & 5.11 & 0 & 0 & $3-30$ & 0 & 0 \\
\hline & & & & & 2.56 & 0 & 0 & $40-185$ & $1-3$ & $\begin{array}{c}0.008- \\
0.05\end{array}$ \\
\hline \multirow[t]{2}{*}{$\begin{array}{l}4,4^{\prime} \text {-Methylene } \\
\text { bis } 2 \text { - } \\
\text { chloroaniline }\end{array}$} & 8 & 280 & 3 & 100 & $15 \mu \mathrm{mol} \mathrm{mol}^{-1}$ & $<1$ & $0 \%$ & $560-1100$ & $1-7$ & $\begin{array}{l}0.001- \\
0.009\end{array}$ \\
\hline & & & & & $5 \mu \mathrm{mol} \mathrm{mol}^{-1}$ & 20 & & & & \\
\hline Acrylamide & 7 & 250 & 6 & 230 & 0.03 & 50 & $20 \%$ & $160-330$ & 0 & 0 \\
\hline $\begin{array}{l}\text { Beryllium and } \\
\text { beryllium } \\
\text { compounds }\end{array}$ & 6 & 390 & 6 & 390 & 0.002 & 50 & $7.1 \%$ & $1500-3000$ & $1-11$ & $\begin{array}{l}0.001- \\
0.005\end{array}$ \\
\hline \multirow[t]{2}{*}{$\begin{array}{l}\text { Refractory } \\
\text { ceramic fibres }\end{array}$} & 2 & 60 & 2 & 50 & 1 fibre $\mathrm{ml}^{-1}$ & 0 & 0 & 0 & $1-2$ & 0 \\
\hline & & & & & 0.1 fibre $\mathrm{ml}^{-1}$ & & & $60-2500$ & $1-2$ & $\begin{array}{c}0.0005- \\
0.004\end{array}$ \\
\hline
\end{tabular}




\begin{tabular}{|c|c|c|c|c|c|c|c|c|c|c|}
\hline 1, 3 Butadiene & & & & & 1.14 & 0 & 0 & $27-100$ & 0 & 0 \\
\hline \multirow[t]{2}{*}{$\begin{array}{l}1,2- \\
\text { Epoxypropane }\end{array}$} & 0 & 0 & 0 & 0 & 12 & 0 & 0 & 0 & 0 & 0 \\
\hline & & & & & 4.8 & & & & & \\
\hline
\end{tabular}

reductions in other health-related conditions, such as nonmalignant respiratory and skin disease. For many of the substances, there are therefore likely to be substantial additional baseline health costs and further unquantified health benefits from introducing an OEL.

In undertaking this type of exercise, there are always many uncertainties. Assumptions made in our methodology along with uncertainties and inaccuracies in the data we have used may have introduced biases in our estimates, the impact of which is not fully captured in the data presented and may result in over or underestimates of the impacts. Potential sources of bias include inappropriate choice of risk estimates, imprecision in estimates of proportions exposed, inaccurate REPs, assumptions about the decline in exposures, the effectiveness of risk management measures already in place and the costs and cost-effectiveness of further risk management measures. At the request of the European Commission, no allowance was made for noncompliance to the limits unlike the previous British study (Hutchings and Rushton, 2012b). In reality, it is unlikely that there will be complete compliance to limits across all 28 Member States.

For some substances, the degree of uncertainty was such that it was not possible to undertake a full impact assessment, particularly where there was a lack of good epidemiological studies from which to derive risk estimates. We generally chose not to use the available toxicological data in these circumstances to avoid problems in trying to extrapolate hazard and risk information for animals to humans and the consequent very large increase in uncertainty that would have been involved.

Despite the uncertainties, the results presented in this paper have contributed to decisions on the merits or otherwise of intervening. The evaluation of the costs and benefits of intervening to reduce the risk from workplace carcinogens were provided in a number of forms, including qualitative descriptions, quantification of impacts and monetary valuation, where possible. This allows the effects from proposed intervention to be understood on a variety of levels, recognising, for example, that monetary valuation of health risks is a controversial area. We believe that it is appropriate to take a weight of evidence approach to prioritising substances for interventions. There were a very wide range of health impacts predicted if the status quo continued, from very low numbers of predicted cancers over the next 60 years for substances such as refractory ceramic fibres (RCF; 60), 1,3 butadiene (160) and vinyl chloride monomer (300) through to $>100000$ cancers over the same period for used mineral oils (130000), DEE (270000) and respirable crystalline silica $(470000)$. These impacts strongly suggest where interventions are needed. However, in addition to cost-benefit analyses, other considerations, such as absolute risk in relation to what is considered to be acceptable risk for occupational exposures, will need to be taken into account when identifying priorities for regulatory interventions. For example, for RCF 50 deaths (60 incident cases) are predicted under the baseline scenario between 2010 and 2069. However, it can also be seen from Figure 2 that only about 10000 workers are currently exposed to RCF in Europe. For comparison, the Health Council of the Netherlands identified a prohibitive risk for occupational carcinogens of 4 per 1000 over a working lifetime (Health Council of The Netherlands, 2012). Although results presented in this paper cannot be used to directly compare with lifetime risk estimates, it is clear that for RCF and some other substances considered in this paper the risk estimates are close to or even over the prohibitive risk limit applied by the Dutch Health Council and other limit-setting organisations.

The main interventions explored in our analyses were the introduction of binding occupational exposure limits, which were broadly chosen to reflect limits that are typically currently found within Europe. It is perhaps surprising that there is often a wide disparity between limits in different European countries; for example, hydrazine ranges from $0.013 \mathrm{mg} \mathrm{m}^{-3}$ in Denmark to $0.13 \mathrm{mg} \mathrm{m}^{-3}$ in Spain, both as 8 -h average values. There were only three substances where the lowest limit tested had an important impact, and even in these cases the reduction in the total number of predicted cancer deaths was modest: respirable crystalline silica $23 \%$, hard wood dust $28 \%$, and rubber fume $39 \%$. For substances such as DEE, the limit would need to be substantially lower than the 'typical' value tested $\left(0.1 \mathrm{mg} \mathrm{m}^{-3}\right.$, as elemental carbon) to have any real impact and probably closer to $0.01 \mathrm{mg} \mathrm{m}^{-3}$.

The costs of compliance were very variable. For many substances, the estimated costs over the 60 years studied were essentially zero because the exposures were currently below the proposed limit. However, for 14 substance-OEL pairs the compliance costs were estimated as probably $>€ 1000$ million; costs were particularly high for hexavalent chromium, respirable crystalline silica and beryllium and its compounds. Although these figures are small in terms of the overall sums of money invested in Europe, in some cases it was considered likely that SMEs would bear the main costs and this could have a serious detrimental effect on their viability.

For only three of the substances considered was there a positive monetised benefit-to-cost ratio, which reflects the discounting of future costs, and the long time lag between intervening and the realisation of the benefits. Although it is a standard economic practice to make these adjustments, we consider it unwise to rely on this one measure of effectiveness of any planned policy changes. We have therefore tried to use a weight of evidence approach highlighting the various pieces of evidence, such as the number of lives lost from inaction and the potential of interventions to prevent future deaths, along with the costs of intervening. In this 
way, we consider a more balanced view of the benefits or otherwise of intervening that can be obtained.

The research has highlighted the limited information available on the hazards, risks and risk management measures in place for many of the substances assessed. We consider that it would be of substantial benefit to be increasingly more proactive in the future in collecting information about occupational carcinogens in the EU. Priority, in particular, should be given to collect better information about MDA and mineral oil as used engine oil, where the potential health impacts are large and the uncertainties are greatest. However, we consider that it is appropriate for the EU to support the development of a surveillance system to collect data on the prevalence and level of exposure to the occupational carcinogens causing the greatest health burden.

Burden of disease measures, such as the AF, which indicates the proportion of a disease attributable to a specific exposure, and the associated numbers, such as attributable deaths or newly occurring cancers and DALYs, are now widely accepted measures of burden of disease and are increasingly used to facilitate identification of major risk factors and high-risk populations, support decisions on priority actions for risk reduction and provide an understanding of important contributions to health inequalities. Our study has extended this to provide additional measures, including estimation of direct and indirect costs of the treatment and the costs of less tangible effects, such as disfigurement, anxiety and so on. The comparison of these with the costs of appropriate intervention strategies allows decision makers to include cost-benefit comparisons as part of their risk reduction plans. This study has demonstrated that a range of measures can be systematically evaluated to aid decision making by the European Commission and social partners.

The results together with other evidence from, for example, the European Scientific Committee on Occupational Exposure Limits, have been used in the review of the Carcinogens Directive with the EU Advisory Committee on Safety and Health via the Working Party on Chemicals, in consultation with industry stakeholders, and social partners. The work has formed the basis of the Impact Assessment completed by the European Commission in advance of legislative change (ec.europa.eu/social/BlobServlet?docId $=15541$ \&langId $=$ en). Setting binding limit values under the Carcinogens Directive could have an important impact on the number of workers in Europe who suffer from work-related cancers. However, even if all the actions evaluated here were introduced there would still be a substantial number of work-related cancers occurring in the future. Further action will be necessary to address this residual risk. One alternative approach that could be considered is to build social partnerships between employers and workers to introduce a culture of continuous improvement in working conditions throughout an industry rather than focussing on minimum standards as is the case with setting binding limit values (Cherrie, 2017).

\section{ACKNOWLEDGEMENTS}

We are grateful for the assistance provided by J Crawford (IOM), $\mathrm{O}$ Warwick and $\mathrm{M}-\mathrm{H}$ Bouhier (ENTEC); T Kauppinen and P Heikkila (Finnish Institute of Occupational Health); H Kromhout (IRAS, University of Utrecht); and L Levy (IEH, Cranfield University). The research was undertaken in collaboration with A Morris, A Angelidis and A Huici-Montagud from the European
Commission DG Employment. The work was funded by the European Commission.

\section{CONFLICT OF INTEREST}

LR was invited to participate in the European Parliament Hearing on 'Protection of Workers Exposure to Carcinogens or Mutagens at Work', October 2016. MvT is a member of the European Union Scientific Committee on Occupational Exposure Limits (SCOEL). The other authors declare no conflict of interest.

\section{REFERENCES}

Cherrie JW (2017) Kaizen. Ann Work Expo Health 61: 398-400.

Creely KS, Cowie H, van Tongeren M, Kromhout H, Tickner J, Cherrie JW (2007) Trends in inhalation exposure-a review of the data in the published scientific literature. Ann Occup Hyg 51: 665-678.

de Vocht F (2005) A database of exposures in the rubber manufacturing industry: design and quality control. Ann Occup Hyg 49: 691-701.

European Commission (2009) EC impact assessment guidelines. Report SEC(2009) 92 http://ec.europa.eu/smart-regulation/impact/ commission_guidelines/docs/iag_2009_en.pdf (accessed 19 August 2015).

Ferlay J, Autier P, Boniol M, Heanue M, Colombet M, Boyle P (2007) Estimates of the cancer incidence and mortality in Europe in 2006. Ann Oncol 18: 581-592.

Health Council of The Netherlands (2012) Guideline for the Calculation of Risk Values for Carcinogenic Compounds. Publication no. 2012/16E. Health Council of The Netherlands: The Hague, The Netherlands.

Hutchings S, Rushton L (2012b) Toward risk reduction: predicting the future burden of occupational cancer. Am J Epidemiol 173: 1069-1077.

Hutchings SJ, Rushton L (2012a) The burden of occupational cancer in Britain. Statistical methodology. Br J Cancer 107: S8-S17.

Kauppinen T, Vincent R, Liukkonen T, Grzebyk M, Kauppinen A, Welling I, Arezes P, Black N, Bochmann F, Campelo F, Costa M, Elsigan G, Goerens R, Kikemenis A, Kromhout H, Miguel S, Mirabelli D,

McEneany R, Pesch B, Plato N, Schlünssen V, Schulze J, Sonntag R, Verougstraete V, De Vicente MA, Wolf J, Zimmermann M, Husgafvel-Pursiainen K, Savolainen K (2006) Occupational exposure to inhalable wood dust in the member states of the European Union. Ann Occup Hyg 50: 549-561.

Kogevinas M, Maqueda J, De la Orden V (2000) Exposición a carcinógenos laborales en España: aplicación de la base de datos CAREX. Arch Prev Riesgoss Labor 3: 153-159.

Levin ML (1953) The occurrence of lung cancer in man. Acta Unio Int Contra Cancrum 9: 531-541.

Mirabelli D, Kauppinen T (2005) Occupational exposures to carcinogens in Italy: an update of CAREX database. Int J Occup Environ Health 11: 53-63.

Nurminen M, Karjalainen A (2001) Epidemiologic estimate of the proportion of fatalities related to occupational factors in Finland. Scand J Work Environ Health 27: 161-213.

Purdue MP, Hutchings SJ, Rushton L, Silverman DT (2015) The proportion of cancer attributable to occupational exposures. Ann Epidemiol 25: 188-192.

Rabl A (2004) Valuation of Health End Points for Children and for Adults. Working Paper.

Rushton L, Hutchings SJ, Fortunato L, Young C, Evans GS, Brown T, Bevan R, Slack R, Holmes P, Bagga S, Cherrie JW, Van Tongeren M (2012) Occupational cancer burden in Great Britain. Br J Cancer 107(S1): S3-S7.

This work is published under the standard license to publish agreement. After 12 months the work will become freely available and the license terms will switch to a Creative Commons AttributionNonCommercial-Share Alike 4.0 Unported License. 